\title{
O uso de mapas conceituais como ferramenta metacognitiva no ensino de Química
}

The use of conceptual maps as a metacognitive tool in chemistry teaching

Laís Conceição Tavares ${ }^{1}$

Regina Celi Sarkis Müller ${ }^{2}$

Adriano Caldeira Fernandes ${ }^{3}$

\section{Resumo}

O presente artigo tem como objetivo propor o uso de mapas conceituais (MCs) como ferramenta metacognitiva no processo de ensino e aprendizagem em química. A pesquisa envolveu estudantes do curso de licenciatura em química, durante a disciplina de química geral teórica II, na Universidade Federal do Pará (UFPA), campus de Belém. Os dados foram obtidos por meio da coleta de MCs construídos pelos discentes. As análises foram realizadas a partir da observação do contato dos estudantes com o objeto de estudo, da forma como os discentes compreendem o conteúdo e da externalização do conhecimento expressa através dos mapas. Os resultados obtidos indicam que através dos MCs é possível compreender melhor as manifestações metacognitivas dos indivíduos, pois os mapas tornam as informações mais acessíveis e permitem perceber a forma como os estudantes compreendem o conteúdo em estudo e como eles relacionam os conceitos em sua estrutura cognitiva. Atualmente é crescente o uso de ferramentas alternativas para o ensino, inclusive na área de ciências da natureza. Desse modo, o uso de MCs foi bem aceito pelos discentes, o que contribuiu significativamente com a formação de futuros docentes, demonstrando a importância desse instrumento para o processo de ensino e aprendizagem.

Palavras chave: mapas conceituais; ensino-aprendizagem; metacognição.

\section{Abstract}

This study aimed to recommend the use of conceptual maps (CMs) as a metacognitive tool in the teaching-learning process in Chemistry. The research was carried out involving students of the chemistry graduation, during the discipline of theoretical general chemistry II, at Universidade Federal do Pará (UFPA), university campus in Belém. The data were obtained through the collection of CMs elaborated by the students. The analyses were carried out based on the observation of students' contact with the object of study, the way in which the students understood the content and the externalization of the knowledge

\footnotetext{
${ }^{1}$ Universidade Federal do Pará | laisctavares@gmail.com

${ }^{2}$ Universidade Federal do Pará | reginasarkis@hotmail.com

${ }^{3}$ Universidade Federal do Pará | acfernandes@ufpa.br
} 
represented through the maps. The results of this study indicated that through the CMs it is possible to better understand the metacognitive manifestations of the individuals, since the maps make the information more accessible and allow understanding how the students understand the content in study and how they relate the concepts in their cognitive structure. Currently, there is an increasing use of alternative tools for the teaching, including in the field of natural sciences, where they are constants, thus, the use of CMs was quite accepted by students, which contributed significantly to the training of future teachers, demonstrating the importance of this instrument for the teaching-learning process.

Keywords: conceptual maps; teaching-learning; metacognitive.

\section{Introdução}

O ensino de química visa contribuir com a formação de cidadãos e permitir o desenvolvimento de capacidade dos alunos de construir conhecimentos e valores úteis para a sua interação com o mundo (YANZO; AMARAL, 2011). A química é uma ciência que está presente no cotidiano e possui uma vasta aplicabilidade nas mais diversas esferas da sociedade e nos variados setores relacionados ao funcionamento do país (BNCC, 2015). No entanto, a disciplina de química é alvo de muitas críticas por parte dos alunos que sentem dificuldades de compreendê-la e não encontram nenhuma aplicação prática de seus conceitos teóricos, o que se reflete no forte desinteresse em aprendê-la (CARVALHO et al., 2007; SILVA et al.; 2017).

Diante disso, muitas pesquisas acadêmicas têm sido desenvolvidas na área do ensino, com o intuito de entender as dificuldades em aprender química e de apresentar auxílios para o processo de aquisição de conhecimento, através da utilização de diferentes recursos metodológicos, como textos, gráficos, tabelas, recursos multimídias e exercícios, além de ressaltar a importância do papel do professor em promover um ensino contextualizado e interdisciplinar, através do qual os alunos possam, cada vez mais, desenvolver suas habilidades (NUNES e ADORNI, 2010; YANZO; AMARAL, 2011; MELO et al., 2011).

Nessa busca por alcançar uma aprendizagem com significados e considerando o contexto em que os estudantes estão inseridos, destaca-se a aprendizagem significativa, proposta por David Ausubel, e que consiste em um processo pelo qual o novo conhecimento deve ser relacionado ao conhecimento prévio presente na estrutura cognitiva do aprendiz, de modo não arbitrário e não literal. A aprendizagem significativa, ao contrário da aprendizagem mecânica, busca aproveitar aquilo que o aluno já sabe, ou seja, os subsunçores presentes na estrutura cognitiva dos indivíduos que são capazes de ancorar uma nova informação, de modo que esta adquira um novo significado para o indivíduo (MOREIRA, 2010).

Para instrumentalizar a teoria da aprendizagem significativa, foram elaborados os mapas conceituais que são ferramentas importantes para auxiliar no processo de ensino e aprendizagem. Ao construírem os mapas conceituais, os indivíduos representam em estruturas gráficas os conteúdos presentes em suas estruturas cognitivas, ligando conceitos de forma hierarquizada, e ao reconstruírem seus mapas, novas informações são incorporadas o que torna possível analisar os mecanismos da cognição humana (AUSUBEL et al.,1978).

Embora não se compreenda exatamente os mecanismos específicos que operam no cérebro, sabe-se que existem redes neurais que estabelecem uma série de ligações entre as 
células cerebrais, e isso nos remete que o ser humano estrutura o conhecimento em sua mente de forma hierárquica (NOVAK, 1984). Desse modo, os MCs se constituem em modelos que expressam processos psicológicos na área da aprendizagem e que representam a organização hierárquica detalhada da relação entre os conceitos presentes na estrutura cognitiva do discente, assim como refletem suas estratégias metacognitivas de aprendizagem.

Segundo Gava; Menezes; Cury (2003), os mapas conceituais são uma ferramenta metacognitiva, de natureza gráfica, capazes de tornar as informações desejadas mais acessíveis, o que faz dos MCs um importante ferramental para expressão de conhecimento. Nesse contexto, esse artigo elenca o seguinte problema de pesquisa: os mapas conceituais podem ser utilizados como instrumentos metacognitivos no processo de ensino e aprendizagem dos conteúdos de química, mas especificamente Equilíbrio Ácido-base?

\section{Metacognição}

A metacognição foi desenvolvida por John Flavell, psicólogo e professor universitário norte-americano, por volta de 1970. Ela consiste em uma teoria que busca explicar todas as operações cognitivas que envolvem o monitoramento e a regulação dos processos cognitivos. Como o próprio termo diz, metacognição é a cognição da cognição, ou seja, o estudo dos processos cognitivos (FLAVELL, 1979). Sobre a metacognição, Beber; Silva; Bonfiglio; (2014) afirma:

A busca do saber fornece a compreensão de como obter motivação para a aprendizagem. A metacognição é a consciência de si próprio, conhecendo seu processo de aprender. Os aspectos conativos (de cognição) estimulam a confiança, a autoestima e o afeto (BEBER; SILVA; BONFIGLIO, 2014, p. 145)

John Flavell definiu a metacognição, respeitando uma consistente teoria de base cognitiva, e conceituou a metacognição como o conhecimento, a consciência e o controle que os indivíduos tem de seus processos cognitivos. Flavell sugeriu que o monitoramento cognitivo poderia ser entendido através das seguintes classes de fenômenos, mencionados no Quadro 1:

De acordo com Boruchovitch \& Santos (2009), a metacognição é usada pelo aluno para que ele reflita sobre sua própria aprendizagem, buscando novas soluções para aprender de modo a conseguir superar obstáculos. Sua importância reside no fato da imensa contribuição que a mesma possui em relação a aprendizagem, pois, a partir do momento em que se toma consciência de como se aprende, o estudante pode buscar estratégias para vencer suas dificuldades e alcançar mais altos graus de aprendizagem, desatrelando-se da dependência extrema, muitas vezes, que os alunos apresentam em relação ao professor no sentido de avaliações externas advindas das atividades propostas pelos docentes.

Beber; Silva; Bonfiglio (2014) afirmam que:

A teoria da metacognição contribui de forma efetiva para que os educadores e educandos desenvolvam suas capacidades motivacionais, criando condições para ampliar o desenvolvimento das competências intrínsecas, potencializando o processo ensino aprendizagem. Compreender os determinantes da aprendizagem e da metacognição leva o sujeito à autoaprendizagem, onde a autoconsciência e a busca da 
superação das limitações devem estar presentes no ato de aprender

(BEBER; SILVA; BONFIGLIO, 2014, p. 145).

\begin{tabular}{|c|c|}
\hline \multicolumn{2}{|c|}{ Modelo de monitoramento cognitivo } \\
\hline Classes de fenômenos & Aplicação na pesquisa \\
\hline $\begin{array}{l}\text { 1) Conhecimento metacognitivo: Conhecimento ou crença que o } \\
\text { indivíduo possui sobre si próprio, acerca das variáveis que afetam o } \\
\text { processo cognitivo, o que favorece as ações de avaliação e de } \\
\text { resolução, a partir do reconhecimento e da representação de } \\
\text { diversas situações cognitivas. }\end{array}$ & $\begin{array}{l}\text { O conhecimento metacognitivo é uma } \\
\text { experiência individual que pode ser } \\
\text { melhor compreendida nos momentos } \\
\text { de socialização em grupo. }\end{array}$ \\
\hline $\begin{array}{l}\text { 2) Experiências metacognitivas: Consistem em experiências } \\
\text { afetivas e cognitivas que permitem a percepção do que pode } \\
\text { acontecer antes, durante ou após a realização de uma tarefa, sendo } \\
\text { sua principal função informar ao indivíduo sobre o ponto em que } \\
\text { ele se encontra, quais as dificuldades e os meios para superá-las. }\end{array}$ & $\begin{array}{l}\text { As experiências cognitivas foram } \\
\text { vivencias durante a sequência de } \\
\text { ensino a partir de apresentação em } \\
\text { slides e do uso de artigos relacionados } \\
\text { ao tema em estudo. }\end{array}$ \\
\hline $\begin{array}{l}\text { 3) Objetivos: Correspondem as metas que impulsionam e mantêm o } \\
\text { empreendimento cognitivo, podendo ser impostos pelo professor ou } \\
\text { selecionados pelo próprio individuo, o qual pode ser modificado no } \\
\text { decorrer da tarefa. }\end{array}$ & $\begin{array}{l}\text { O objetivo principal foialcançar a } \\
\text { aprendizagem do conteúdo de } \\
\text { Equilibrio Ácido-base, através de } \\
\text { estratégias metacognitivas. }\end{array}$ \\
\hline $\begin{array}{l}\text { 4) Ações: São as estratégias utilizadas para potencializar e avaliar o } \\
\text { processo cognitivo, com a finalidade de conduzir ao } \\
\text { desenvolvimento cognitivo e podem sugerir o progresso cognitivo e } \\
\text { metacognitvo. }\end{array}$ & $\begin{array}{l}\text { Elaboração e reelaboração de mapas } \\
\text { conceituais sobre intermédio do } \\
\text { professor. }\end{array}$ \\
\hline
\end{tabular}

Quadro 1. Modelo de monitoramento metacognitvo com classes de fenômenos adaptadas à pesquisa (Fonte: FLAVELL,1979; RIBEIRO, 2003; DEFFENDI e SCHELINI, 2016).

\section{Mapas conceituais (MCs)}

Os mapas conceituais foram inicialmente desenvolvidos por Joseph Novak na década de 1970, na Universidade de Cornell, nos Estados Unidos, fundamentados na Teoria da Aprendizagem Significativa (TAS), de David Ausubel. Baseado na TAS e a partir de observações em sala de aula, Novak defende que a teoria de Ausubel oferece uma fundamentação intelectual sólida para a implementação de situações novas no processo de ensino-aprendizagem, que poderão levar a melhorias na educação (NOVAK, 1977, 1984).

Segundo Moreira (1993) de um modo geral, os mapas conceituais são diagramas que indicam relação entre conceitos à luz dos princípios da diferenciação progressiva e reconciliação integradora. As relações entre conceitos são expressas na forma de proposições, uma proposição consiste em dois ou mais termos conceptuais ligados por palavras de modo a formar uma unidade semântica (NOVAK, 1984). As palavras que unem dois conceitos são chamadas de termos de ligação ou conectivos, sendo que os mesmos não podem ser curtos e devem especificar o relacionamento dos conceitos de forma significativa.

Os mapas não podem ser confundidos com diagrama de fluxo ou organograma, diagrama classificatório, tão pouco com mapas mentais, pois enquanto os MCs são diagramas que apresentam uma organização hierárquica repleta de relações significativas, 
todos os demais exemplos não estão organizados hierarquicamente (MOREIRA, 2010). A construção de um mapa conceitual pode ser feita de várias formas, dependendo da disposição dos conceitos principais e subjacentes. Basicamente as relações hierárquicas seguem um sentido, seja linear ou radial; partindo do centro ou do topo do diagrama.

A diferenciação progressiva e a reconciliação integradora são os princípios mais importantes que regem a construção dos mapas conceituais. No primeiro, há uma relação de inclusão de um conceito mais geral a conceitos mais específicos que são incluídos como extensão desse conceito mais geral; algo semelhante ao "do macro ao micro". No segundo, ao contrário da diferenciação, esse mecanismo parte do conteúdo mais específico para o mais geral buscando relacioná-lo e ampliar os conceitos envolvidos no conteúdo para níveis de formulação mais gerais (MOREIRA 1999).

O uso dos mapas conceituais como ferramenta pedagógica está ligado ao fato de sua elaboração possibilitar uma forma diferenciada de relacionar os conceitos, exigindo dos estudantes, pensamento integrado. O mapa não dispensa a explicação do professor, logo os mapas devem ser explicados por seus autores (MOREIRA, 1992). A construção de mapas pode ser realizada diretamente pelos alunos, o que permite acompanhar o processo de avaliação e de ensino- aprendizagem (PACHECO; DAMASIO, 2009).

\section{Procedimentos Metodológicos}

\section{Tipo de pesquisa}

Essa pesquisa se caracteriza como qualitativa pois procura descrever, compreender e explicar a complexidade e a interpretação do fenômeno em estudo, a partir de uma análise criteriosa das informações (MORAES E GALIAZZI, 2011). O tipo de pesquisa empregado foi o estudo de caso, visto que buscou-se, por meio de observações, compreender determinadas situações a partir de análises do pesquisador dentro do contexto de graduandos do curso de licenciatura em química (LEO; GONÇALVES, 2010).

\section{Contexto da pesquisa}

A pesquisa foi desenvolvida com 35 alunos do sétimo semestre do curso de Licenciatura em Química da Universidade Federal do Pará, ao longo da disciplina de química geral teórica II. A escolha de alunos do curso de Licenciatura em Química foi motivada pelos mesmos já terem feito o uso de mapas conceituais em outra disciplina (química geral teórica I) e, também, pela necessidade de se incentivar e de aprofundar os estudos de ferramentas para o ensino. Desse modo, acredita-se que o uso de mapas conceituais, como instrumentos de ensino e aprendizagem, pode trazer contribuições significativas para a formação desses futuros docentes (MELO et al., 2011).

\section{Caracterização da pesquisa}

Uma sequência de ensino foi preparada e aplicada para implementação de conceitos pertencente à disciplina de química geral teórica II. Os dados foram coletados ao longo da disciplina, a partir das atividades de elaboração e reelaboração de mapas conceituais, que foram construídos pelos alunos, individualmente e sob orientação do professor. Os mapas conceituais elaborados no início da unidade de ensino receberam o nome de mapas 
conceituais iniciais ( $\mathrm{MCls}$ ) e os mapas produzidos no término da unidade de ensino receberam o nome de mapas conceituais finais (MCFs).

A disciplina procedeu com a sequência ensino, conforme mostra o fluxograma a seguir:

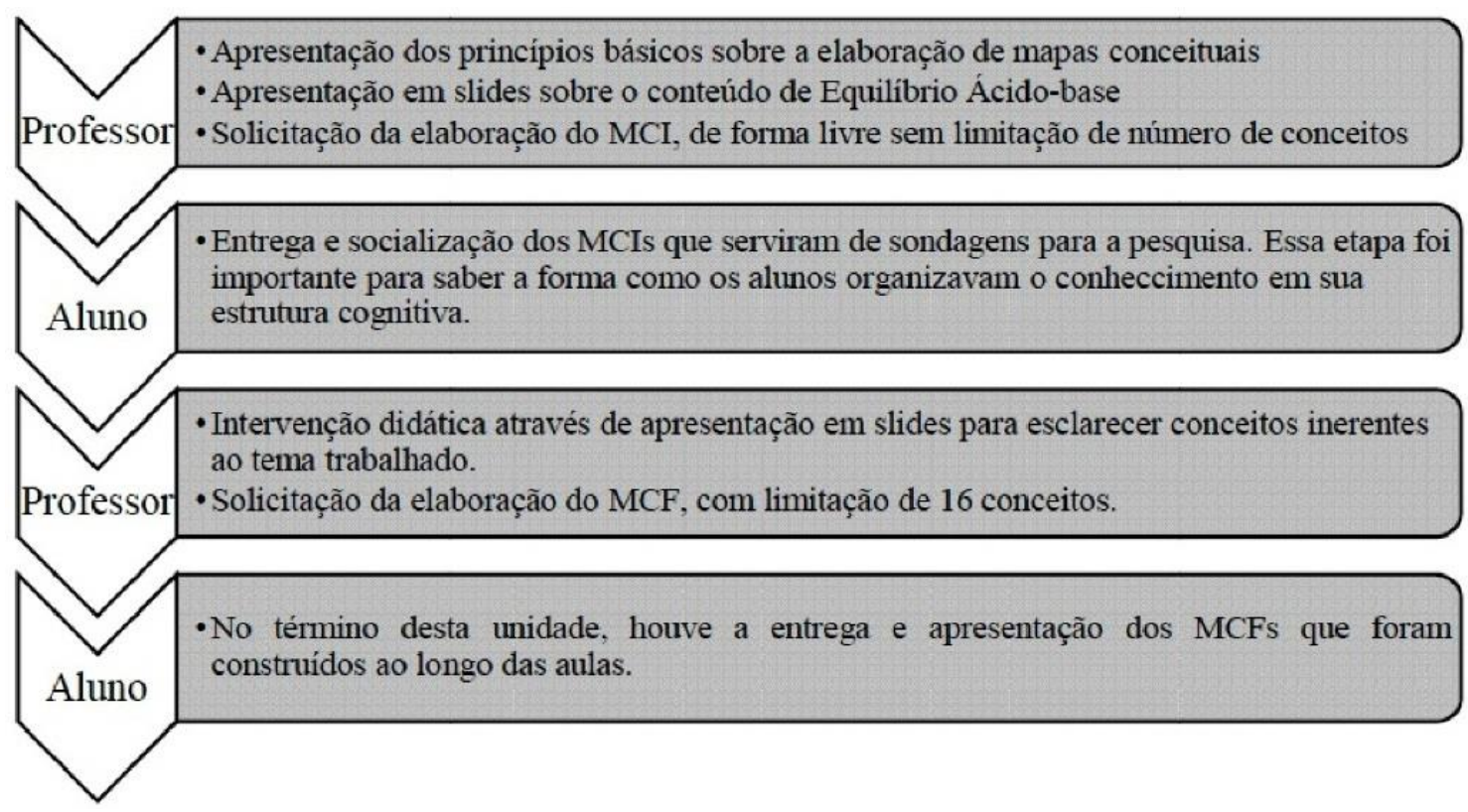

Figura 1. Fluxograma da sequência de ensino aplicada na pesquisa.

Fundamentados na obra de Novak e tendo como base a teoria cognitiva de aprendizagem de Ausubel, os mapas construídos foram avaliados sob os seguintes parâmetros de análise: presença dos principais conceitos, proposições com sentido lógico e organização hierárquica. Tais parâmetros de análise foram selecionados a partir da leitura de outros artigos sobre mapas conceituais (RUIZ-MORENO et al., 2007; AGUIAR; CORREIA, 2013; CICUTO; CORREIA, 2013) e baseando-se na própria definição de mapas conceituais, que apresenta os mesmos como diagramas que mostram relações entre conceitos em uma estrutura hierárquica de proposições, desse modo, conceitos, proposições e hierarquias são os critérios importantes que auxiliam na interpretação dos mapas conceituais. Para cada parâmetro de análise foi atribuída uma pontuação de 0\% à 100\%, posteriormente calculouse a média entre elas para dar a pontuação final aos MCs dos alunos, e a partir delas, os mapas receberam os seguintes conceitos: insuficiente $(0 \%-49 \%)$, regular (50\% - 69\%), bom (70\% - 89\%) e excelente (90\% - 100\%).

\section{Presença dos principais conceitos}

Através desse critério buscou-se verificar se o aluno utilizou os conceitos mais relevantes pertencentes à temática trabalhada, tais como: [equilíbrio iônico ou equilíbrio ácido-base]; [Lewis]; [Arrhenius]; [Bronsted-Lowry]; [ácidos]; [bases]; [água ou equilíbrio aquoso]; [força], observando-se a qualidade e a quantidade de conceitos usados pelos discentes. $\mathrm{Na}$ análise do conteúdo buscou-se comparar os conceitos presentes no $\mathrm{MCl}$ e no MCF para verificar se os discentes souberam selecionar os principais conceitos relacionados ao tema de Equilíbrio Ácido-base, para identificar a evolução dos conceitos estudados, assim como para perceber a tomada de consciência da relevância do estudo desses conceitos, visto que muitas vezes os alunos se distanciam da proposta feita pelo docente, o 
que pode ser verificado nas escolhas dos conceitos e na interligação entre os mesmos. Quando um aluno se distancia do tema proposto, ele não utiliza os conceitos fundamentais relacionados ao tema em estudo, e por isso a avaliação de seu MC sofre prejuízos, pois torna-se mais difícil analisar a construção do conhecimento na estrutura cognitiva do aprendiz (AGUIAR; CORREIA, 2013).

\section{Proposições com sentido lógico}

Para melhor compreensão da aprendizagem do aluno por meio da análise dos MCs é necessário avaliar as proposições elaboradas pelos discentes. Segundo Novak (1984), uma vez que uma pessoa constrói um mapa conceitual, ela explicita e manifesta conceitos e proposições, e desse modo o professor pode verificar a validade dessas proposições, e assim contribuir com o processo de ensino-aprendizagem. Em relação a esse critério buscou-se observar se os discentes construíram proposições com sentido lógico do ponto de vista semântico e científico. Foi observado se as proposições se encontravam estruturadas do modo correto, isto é, com a presença de termos de ligação entre conceitos e se as mesmas apresentavam elementos semânticos e sintáticos para que eles transmitissem uma mensagem completa e coerente. Buscou-se analisar a evolução na construção das proposições através da comparação entre os mapas iniciais e finais.

\section{Organização hierárquica}

Segundo Aguiar e Correia (2013), um mapa conceitual pode ser mais facilmente compreendido se sua estrutura hierárquica estiver bem organizada, e isso pode ser revelado através da presença de diferenciação progressiva e de reconciliação integradora. Nesse parâmetro de análise foi observado se os mapas apresentavam boa organização, se eram criativos, se possuem níveis hierárquicos de acordo com os conceitos mais gerais até os mais específicos. Também buscou-se averiguar se houve uma melhora na organização hierárquica dos mapas através da comparação entre o MCl e o MCF, e a partir daí tentou-se mostrar como os alunos interpretam o conteúdo e a forma como eles relacionam os conceitos entre si (NOVAK, 1984).

Espera-se que a produção de novas versões dos MCs possibilite aos alunos a reconstrução das relações entre os conceitos, para permitir a revisão do conteúdo e para contribuir com a evolução na estrutura hierárquica apresentada nos mapas. Os alunos, ao revisarem seus mapas, podem tomar consciência de erros e de acertos, além de acrescentar informações e de construir o conhecimento, o que contribui para o desenvolvimento metacognitivo dos estudantes.

\section{Resultados e discussões}

Os 70 mapas produzidos pelos alunos, $35 \mathrm{MCls}$ (mapa conceituais iniciais) e $35 \mathrm{MCFs}$ (mapa conceituais finais), foram analisados qualitativamente, para conferir a evolução metacognitiva dos discentes. As análises foram baseadas nos critérios pré-estabelecidos para averiguar a presença dos principais conceitos relacionados ao tema em estudo, para verificar se os alunos utilizaram os conceitos de forma coerente; para conferir o uso de proposições com sentido lógico e para atentar à presença de uma estrutura hierárquica organizada dos MCs. 


\title{
Presença dos principais conceitos
}

$\mathrm{Na}$ construção dos $\mathrm{MCl}$ s, houve uma grande variação no número de conceitos usados pelos discentes, o que pode ser explicado devido a primeira construção ter ocorrido de forma livre, sem limitação do número de conceitos que poderiam ser utilizados pelos alunos em seus MCs. Dos $35 \mathrm{MCls}$ analisados, somente 16 alunos conseguiram utilizar os conceitos mais relevantes relacionados ao tema de Equilíbrio Ácido-Base, o que corresponde a 45,71\%(16), ou seja, menos da metade dos discentes conseguiu identificar e selecionar os conceitos mais importantes sobre o conteúdo em estudo. Sabendo-se que os mapas conceituais são ferramentas metacognitivas que tornam mais acessíveis as informações presentes na estrutura cognitiva dos indivíduos (Gava; Menezes; Cury, 2003), e diante do resultado apresentado pode-se aferir que os discentes demonstraram pouco domínio sobre o conteúdo trabalhado, em vista da baixa ancoragem de conceitos em suas estruturas cognitiva.

Entretanto, na construção dos MCFs, verificou-se que a maioria dos discentes conseguiu abarcar os principais conceitos relacionados ao tema de trabalho. Dos 35 MCFs analisados, 74,28\%(26) apresentaram os conceitos básicos relacionados ao tema, o que evidencia um resultado favorável, visto que nessa segunda construção houve uma limitação do número de conceitos, o que fez os discentes selecionarem os principais conceitos. Porém, cerca de 25,71\%(9) dos discentes nas versões finais de seus mapas ainda apresentaram dificuldades na escolha dos principais conceitos e acabaram selecionando conceitos desnecessários que os distanciaram do tema, causando prejuízos a construção de seus mapas.

O resultado positivo em relação a esse critério de análise pode ser atribuído a postura reflexiva desenvolvida pelos alunos, que ao produzirem os $\mathrm{MCls}$ receberam o auxílio do professor quanto aos erros e acertos, e num momento posterior puderam através de intensas revisões contínuas, desenvolver empreendimentos cognitivos e metacognitvos que os possibilitam selecionar, entender e refletir sobre a informação, como afirma Almeida (2002) afirma:

\begin{abstract}
Para que um empreendimento cognitivo seja bem sucedido parece ser necessário, além de um conhecimento adequado, conscientização e controle suficientes desse conhecimento. A metacognição compreende, então, duas classes de atividades cognitivas, a conscientização do domínio específico do conhecimento sobre o seu próprio processo cognitivo e o domínio de diferentes formas de proceder. Assim, a metacognição implica conhecimento sobre os nossos próprios processos de conhecer, ou seja, de aprender (ALMEIDA, 2002, p. 425).
\end{abstract}

\section{Proposições com sentido lógico}

Para o indivíduo aprender significativamente, ele precisa relacionar novos conhecimentos com as proposições e conceitos mais relevantes que já conhece, mostrando como os indivíduos englobam os conceitos entre si. Dos 35 discentes que participaram da pesquisa, 80\%(28), construíram mais proposições válidas semânticas e científicas em seus $\mathrm{MCls}$, do que inválidas. Isso pode ser esclarecido pelo fato de os mesmos já terem utilizado 
essa ferramenta de ensino, portanto boa parte dos estudantes não apresentaram dificuldades na estruturação das proposições.

Ao analisar os MCFs, o resultado obtido foi novamente $80 \%(28)$ de alunos que apresentaram a maioria de proposições válidas em seus mapas. Na construção dos mapas conceituais finais, o professor limitou o número de conceitos para 16, e diante disso alguns alunos ao reduzirem o número de conceitos, acabaram excluindo termos de ligações, o que acarretou no prejuízo das proposições. Diante disso, autores afirmam que o uso de um termo de ligação que expresse incerteza indica uma compreensão parcial sobre o conteúdo e a ausência do termo de ligação impede o entendimento da relação conceitual, originando um mapa mental (NOVAK, 2002; DAVIS, 2011). Sobre proposições inválidas, observa-se proposição a seguir, que foi extraída do MCF de um dos alunos envolvidos na pesquisa, denominado de A8:

\section{Equilíbrio iônico $\rightarrow$ ocorre em $\rightarrow \quad$ ácidos, bases e sais}

Percebe-se que o aluno ao construir o seu MCF, na tentativa de reduzir o número de conceitos, acabou por agregar 3 conceitos em uma única caixa, construindo assim uma proposição inválida. Dessa forma, proposições sem clareza semântica ou erros conceituais sugerem uma compreensão limitada ou inapropriada sobre o mapa conceitual (CICUTO; CORREIA, 2013).

Observemos os trechos a diante:

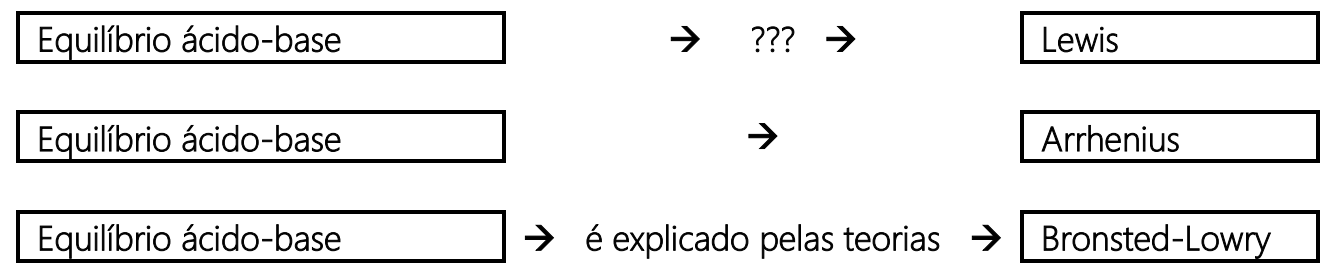

Ao analisar os fragmentos acima, retirados do MCF do aluno A8, pode-se aferir que o mesmo cometeu equívocos estruturais, como a ausência de termos de ligação, o que comprometeu o entendimento de seu mapa conceitual.

No entanto, pode-se afirmar que a maioria dos alunos construiu um número de proposições válidas maior do que o número de proposições inválidas, como podemos verificar no trecho a diante:

\section{Equilíbrio iônico $\rightarrow$ envolve $\rightarrow$ Reações ácido-base $\rightarrow$ ocorre geralmente em $\rightarrow$ Solução aquosa}

De acordo com Moraes; Santana; Viana-Barbosa (2011), as proposições são termos relevantes em mapas conceituais que permitem avaliar a aprendizagem dos alunos. Portanto, de um modo geral, percebeu-se a evolução dos discentes em relação a esse critério de análise, visto que ao reconstruírem seus mapas, os discentes souberam selecionar conceitos utilizados, além de empregar bons conectivos, o que aumentou o significado semântico das proposições.

Acredita-se que os discentes, ao produzirem e explicarem os seus MCls, puderam externar mais claramente o modo como os mesmos selecionaram os conceitos, a forma como criaram as proposições e como estruturaram seus mapas. A partir das tarefas apresentadas, o professor atuou como mediador do processo de ensino-aprendizagem ao 
estimular o aluno a desenvolver um olhar de introspecção para seus processos metacognitivos, o que possibilitou ao docente identificar o que é passível de ensino e o quais as limitações dos alunos. Dessa forma, os discentes ao construírem MCF puderam aumentar o grau de clareza semântica das proposições, corrigindo erros gramaticais e estruturais para melhor representar as relações entre conceitos.

\section{Organização hierárquica}

Segundo Moraes; Santana; Viana-Barbosa (2011), um mapa conceitual "bem estruturado" é melhor do que um mapa conceitual "mal estruturado", se ambos apresentarem o mesmo conteúdo. Desse modo, a estrutura dos MCs é fator importante para a compreensão detalhada da relação entre os conceitos presentes na estrutura cognitiva dos indivíduos, pois ao se avaliar a qualidade em termos de estrutura e conceitos, pode-se verificar a ocorrência ou não da aprendizagem significativa.

Em relação à organização hierárquica dos $\mathrm{MCls}$, verificou-se uma grande variação na quantidade de níveis hierárquicos e uma inversão na derivação progressiva, pois os conceitos partiam dos mais específicos para os mais gerais e abrangentes em alguns mapas. Porém, de um modo geral, verificou-se estruturas hierárquicas bem definidas, visto que 80\%(28) dos mapas estavam bem estruturados; porém 20\%(7) da turma apresentou problemas na estrutura organizacional e hierárquica de seus mapas, o que evidenciou uma dificuldade em relacionar os conceitos com seus subordinados (NOVAK, 1984).

Ao analisar os MCFs, novamente $80 \%(28)$ dos mapas dos alunos apresentaram boas estruturas hierárquicas, mostrando que os discentes ao refazerem seus mapas, conseguiram alcançar uma organização hierárquica mais adequada, porém, alguns alunos melhoraram a hierarquia, mas permaneceram com a mesma pontuação porque acabaram prejudicando outros critérios de análise, como as proposições ou a seleção de conceitos.

Análise dos mapas conceituais do aluno A2

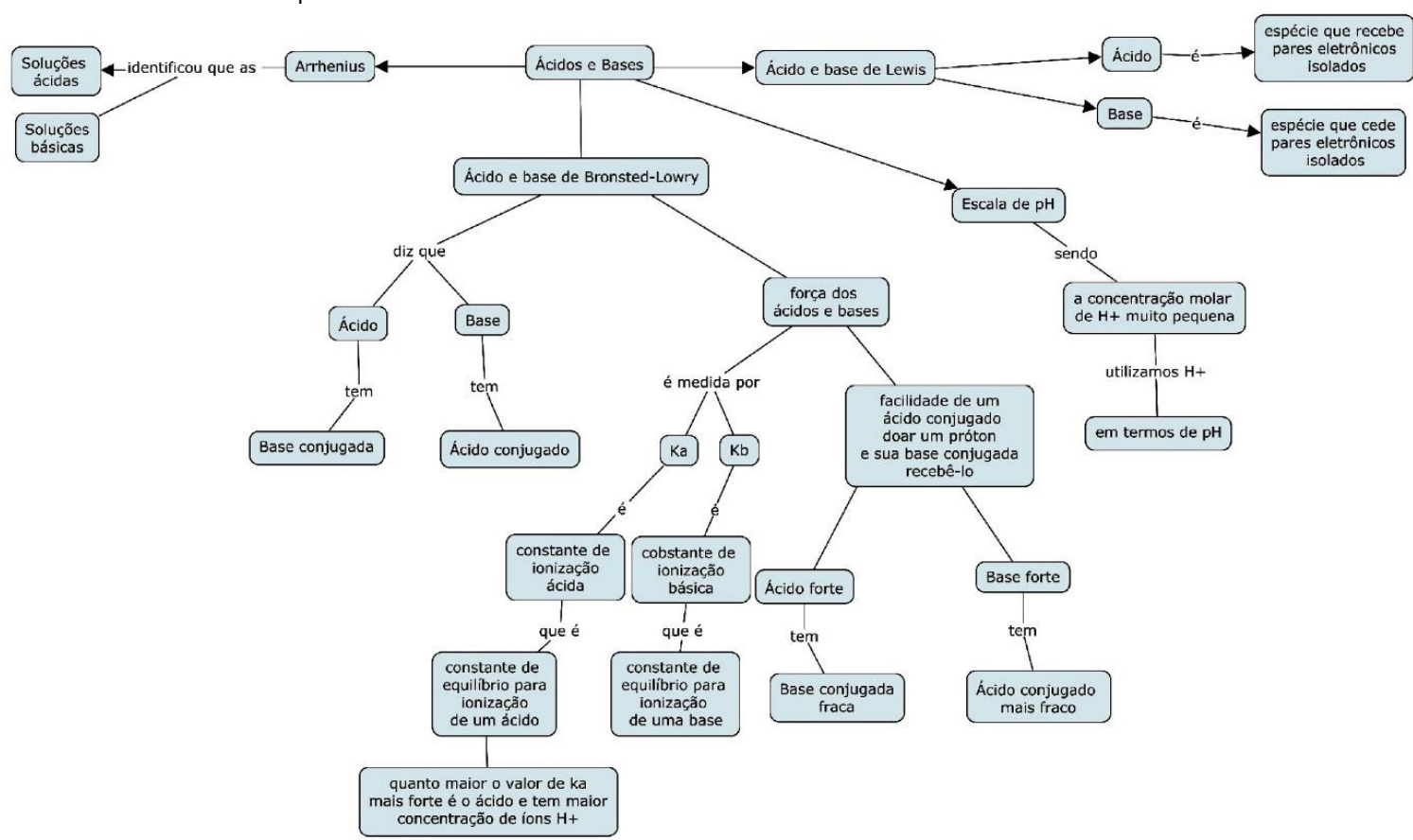

Figura 2. $\mathrm{MCl}$ produzido pelo aluno A2 ao longo da disciplina de Química Geral Teórica II, sobre o conteúdo de Equilíbrio Ácido-base (Conceito Regular). (Fonte: Dados da pesquisa). 
Os mapas conceituais do aluno A2 foram selecionados para melhor exemplificar o processo de aprendizagem do aluno, visto que o conceito de seu $\mathrm{MCl}$ passou de regular para excelente em seu MCF, apresentando uma grande evolução na construção de seus MCs.

Ao analisar o $\mathrm{MCl}$ do aluno A2 (Figura 1), pode-se perceber que o discente tem conhecimento sobre o tema proposto, pois foram identificados em seu mapa conceitos relevantes como [Arrhenius]; [Ácido e base de Bronsted-Lowry]; [Ácido e base de Lewis]; [ácido]; [base], porém ao se referir ao tema em estudo que é [equilíbrio iônico ou equilíbrio ácido-base], o aluno mencionou [ácidos e bases], descaracterizando o título do conteúdo trabalhado, o que sugere uma compreensão confusa ou superficial do conteúdo.

Em relação às proposições, o discente ao invés de utilizar um conceito em cada caixa, colocou dois conceitos dentro de uma caixa só, como pode-se observar na própria caixa central: [ácidos e bases], o que configura um erro na estrutura da proposição. Também foi identificado a ausência de conectivos ou termos de ligação em suas proposições, como observa-se no fragmento a seguir:

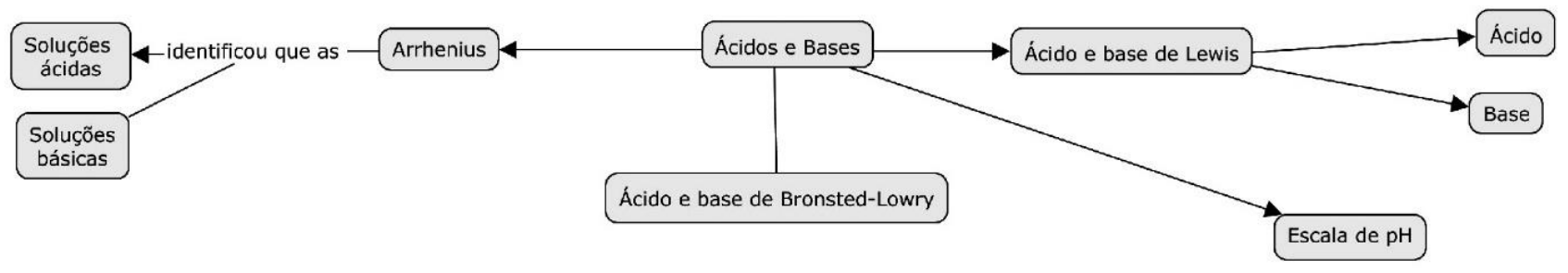

Figura 3. Fragmento do $\mathrm{MCl}$ produzido pelo aluno A2 (Fonte: Dados da pesquisa).

Percebe-se que aluno A2 iniciou o mapa e pouco utilizou termos de ligação, o que acarretou em proposições inválidas. Outro fator que faz a proposição se tornar inválida é o uso de textos explicativos no lugar de conceitos, como também foi observado no mapa do aluno, conforme mostra o trecho abaixo:

\begin{tabular}{|l|l|} 
força dos ácidos e bases & $\rightarrow$ ??? $\rightarrow \quad \begin{array}{l}\text { facilidade de um ácido conjugado doar um } \\
\text { próton e sua base conjugada recebê-lo }\end{array}$ \\
\hline
\end{tabular}

Ao analisar a estrutura hierárquica de um mapa, espera-se que o título do conteúdo esteja em destaque e em área central, e posteriormente os conceitos mais específicos aparecem hierarquicamente de acordo com a ordem de relevância. No caso do $\mathrm{MCl}$ do aluno $A 2$, nota-se que o aluno não destacou o conceito central, além de não seguir uma sequência lógica nas ramificações de seu mapa, o que não representa uma hierarquia adequada.

No entanto, na construção do MCF, pode-se perceber que o aluno conseguiu construir um mapa conceitual bem melhor do que o primeiro, corrigindo os erros cometidos no $\mathrm{MCl}$, como mostra a Figura 4.

No MCF do aluno A2 verificou-se a presença dos principais conceitos relacionados ao tema de forma clara, assim como o aluno corrigiu os erros nas proposições, colocando conectivos sempre entre os conceitos, além de utilizar somente um conceito em cada caixa, sem confundir textos explicativos com conceitos, o que resultou na elaboração de proposições válidas semântica e cientificamente. 
De um modo geral, foi observado a partir das comparações entre o MCl e o MCF, um aumento progressivo na compreensão do conteúdo, o que se refletiu em novas relações hierárquicas entre os conceitos, partindo de conceitos mais gerais e abrangentes tais como: [Equilíbrio lônico]; [Equilíbrio Ácido-base]; [Ácido-base de Arrhenius]; [Ácido-base de Bronsted-Lowry]; [Ácido-base de Lewis]; até os mais específicos e menos abrangentes, como: [Pares conjugados]; [Força dos ácidos e bases]; [Auto-ionização da água].

Acredita-se que a organização hierárquica seja um forte indicativo para o acompanhamento da estrutura cognitiva do aprendiz, além do desenvolvimento de seus processos metacognitvos, como pode-se identificar no MCF do aluno A2 que mostra o conceito principal central e em destaque, além da ótima organização hierárquica, com a presença de derivações progressivas e de reconciliações integrativas (ligações transversais), o que representa uma evolução na aprendizagem do aluno.

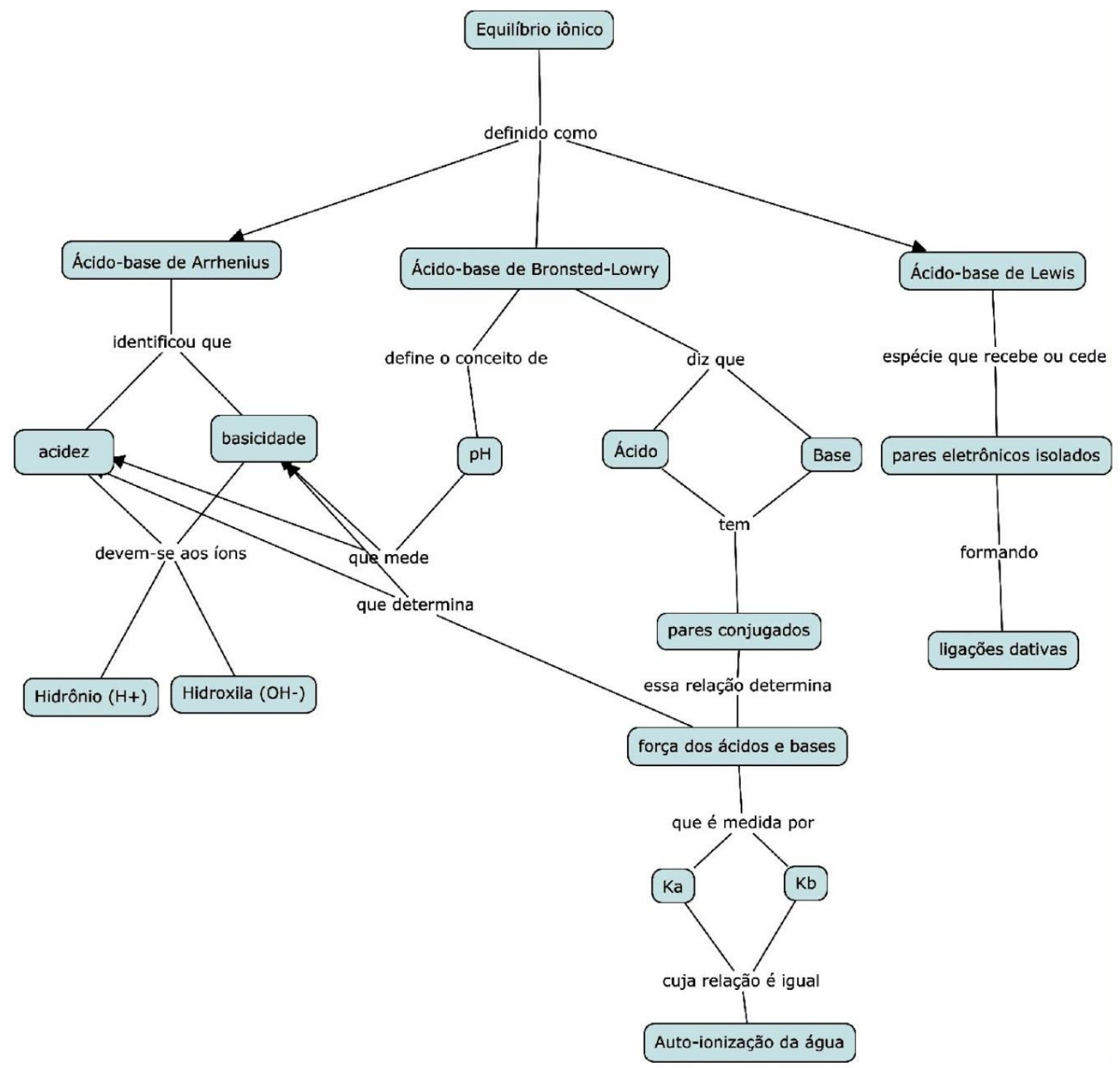

Figura 4. MCF produzido pelo aluno A2 evidenciando a evolução de sua aprendizagem (Conceito

Excelente) (Fonte: Dados da pesquisa). 
Análise geral dos mapas conceituais

A partir dos critérios de análise, os 70 mapas conceituais (35 MCls e 35 MCFs) foram classificados nos seguintes conceitos: insuficiente, regular, bom e excelente, conforme sintetiza a Figura 5. Do universo de 35 alunos que participaram da pesquisa, houve uma diminuição no número de conceitos insuficientes, regulares e bons, em contrapartida houve um aumento do número de conceitos excelentes.

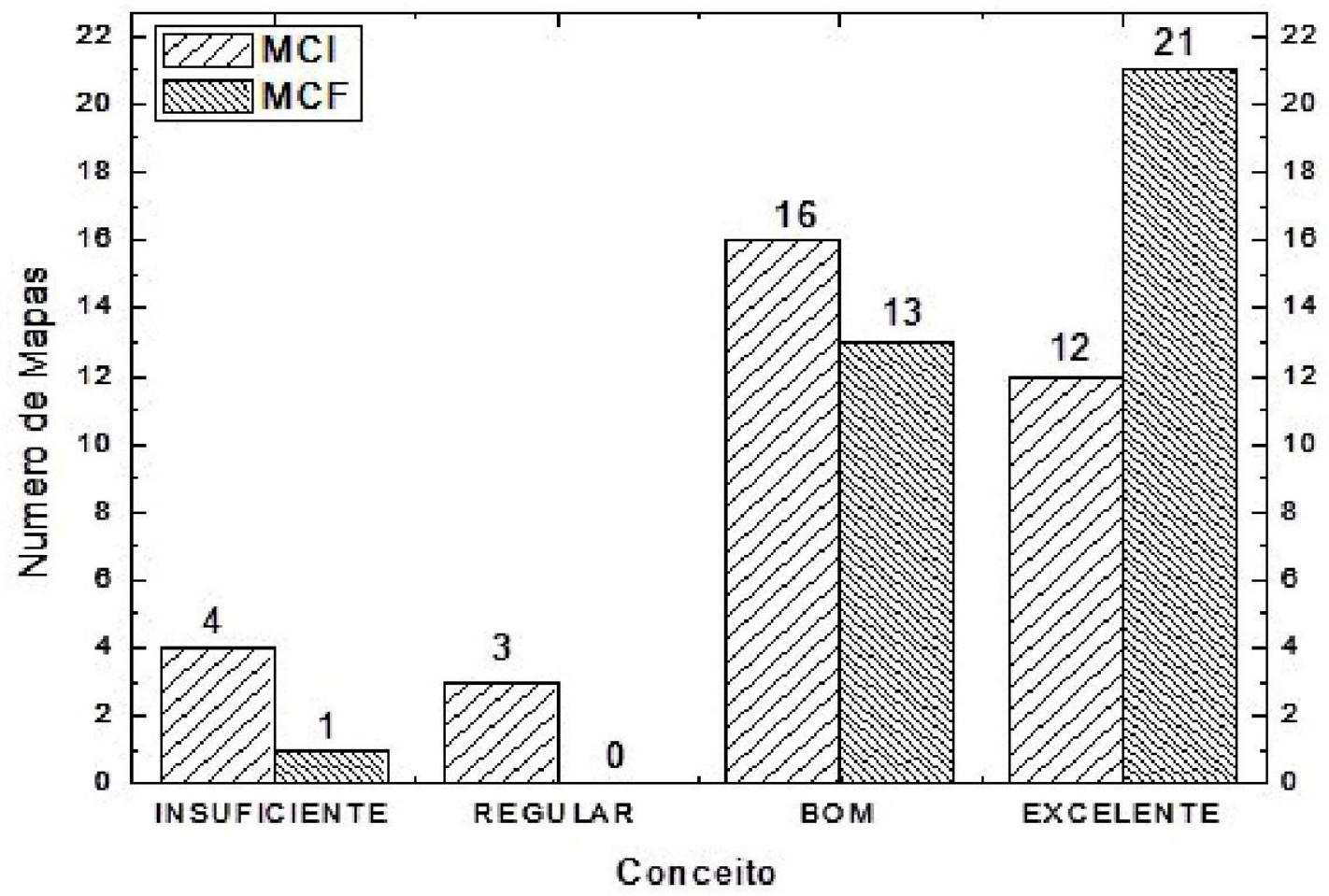

Figura 5. Gráfico de comparação dos conceitos dos mapas MCl e MCF elaborados pelos alunos no decorrer da disciplina de Química Geral Teórica II (Fonte: Dados da pesquisa).

Os dados para a construção do gráfico foram retirados do quadro 2:

\begin{tabular}{|c|c|c|c|c|c|}
\hline DISCENTE & $\begin{array}{c}\text { CONCEITO } \\
\text { MCI }\end{array}$ & $\begin{array}{c}\text { CONCEITO } \\
\text { MCF }\end{array}$ & DISCENTE & $\begin{array}{c}\text { CONCEITO } \\
\text { MCI }\end{array}$ & $\begin{array}{c}\text { CONCEITO } \\
\text { MCF }\end{array}$ \\
\hline A1 & BOM & EXC & A19 & BOM & EXC \\
\hline A2 & REG & EXC & A20 & EXC & EXC \\
\hline A3 & BOM & EXC & A21 & BOM & BOM \\
\hline A4 & EXC & BOM & A22 & INS & BOM \\
\hline A5 & BOM & BOM & A23 & INS & INS \\
\hline A6 & BOM & BOM & A24 & EXC & EXC \\
\hline A7 & BOM & EXC & A25 & REG & EXC \\
\hline A8 & INS & BOM & A26 & BOM & BOM \\
\hline A9 & EXC & EXC & A27 & BOM & EXC \\
\hline A10 & BOM & BOM & A28 & EXC & EXC \\
\hline A11 & EXC & EXC & A29 & BOM & EXC \\
\hline A12 & INS & BOM & A30 & BOM & EXC \\
\hline A13 & BOM & EXC & A31 & EXC & EXC \\
\hline A14 & REG & BOM & A32 & EXC & EXC \\
\hline A15 & EXC & EXC & A33 & EXC & EXC \\
\hline A16 & BOM & BOM & A34 & EXC & EXC \\
\hline A17 & BOM & BOM & A35 & EXC & EXC \\
\hline A18 & BOM & BOM & & & \\
\hline
\end{tabular}

Quadro 2. Conceitos dos MCls e MCFs (Fonte: Dados da pesquisa). 
Comparando os conceitos obtidos nos MCls e com os conceitos obtidos no MCFs, verificou-se que 33 alunos apresentaram uma evolução da aprendizagem, visto que ou elevaram seus conceitos ou permaneceram com o mesmo conceito, embora tenham ocorrido alguns erros em seus MCs, 1 aluno teve uma queda nos níveis de aprendizagem, caindo de excelente para bom, em razão de problemas relacionadas as proposições e 1 aluno permaneceu com conceito insuficiente não apresentando melhora em seus mapeamentos.

Sendo assim a pesquisa atingiu um resultado satisfatório de 90,28\% de evolução da aprendizagem, ou seja, a cada 10 alunos, aproximadamente 9 conseguiram alcançar os objetivos das atividades na construção do conhecimento sobre Equilíbrio Ácido-base. Acredita-se que um dos fatores que contribuiu para o alcance de bons resultados foi o fato dos alunos já terem vivenciado uma experiência de ensino com o uso de mapas conceituais na primeira unidade sobre Equilíbrio Químico, além do esforço e determinação dos discentes durante a construção dos mapas.

Nas versões finais dos mapas conceituais identificou-se a presença dos conceitos mais relevantes relacionados ao tema, o que mostrou a ocorrência da ancoragem de novas informações nas estruturas cognitivas dos discentes. Também percebeu-se um aumento do número de proposições com sentido lógico, semântico e cientificamente, o que evidencia uma melhor compreensão sobre o conteúdo trabalhado, assim como sobre as interrelações entre os conceitos. Outro fator que merece destaque é a organização hierárquica dos mapas, pois os discentes, ao final da sequência de ensino, conseguiram construir MCs com a presença de derivações progressivas, isto é, partindo de conceitos mais gerais até os mais específicos, mostrando uma compreensão mais clara do conteúdo.

Sendo assim, ao analisar os mapas dos estudantes a partir dos critérios de análise: presença dos principais conceitos; proposições com sentido lógico e organização hierárquica, é possível não somente construir novos conhecimentos nas estruturas cognitivas dos discentes como também desenvolver neles estratégias metacognitivas, contribuindo assim com o processo de ensino-aprendizagem.

\section{Considerações Finais}

Os resultados das análises dos mapas conceituais elaborados no decorrer da disciplina de Química Geral Teórica II, indicaram que os MCs são ferramentas importantes para o auxílio dos discentes na organização e na construção do conhecimento e para aplicação de estratégias metacognitivos, haja vista que para a elaboração dos mapas foi necessário um esforço cognitivo para identificar os conceitos considerados mais importantes e para criação de proposições, além das reflexões e modificações que os discentes faziam cada vez que um novo conhecimento era incorporado a sua estrutura cognitiva. Foi notória a prédisposição dos discentes em apropriar-se de mais informações e de encadear novos conceitos em seus mapas, o que representa um fator favorável ao processo de ensino e aprendizagem como descreve a teoria de Ausubel.

Dessa forma, a pesquisa desenvolvida demonstrou que o uso de MCs contribui com a formação de futuros professores, pois aumenta seus campos de visão em relação ao processo de ensino e aprendizagem e auxilia na avaliação metacognitiva dos indivíduos, destacando a importância dessa ferramenta para o ensino em todas as áreas do conhecimento, em especial no Ensino de Química. 


\section{Referências}

AGUIAR, J. G.; CORREIA, P. R. M. Como fazer bons mapas conceituais? Estabelecendo parâmetros de referências e propondo atividades de treinamento. Revista Brasileira de Pesquisa em Educação em Ciências, v. 13, n. 2, 2013.

ALMEIDA, M. A. Estratégias metacognitivas: uma possibilidade no ensino de enfermagem. Rev. Bras. Enferm., Brasília, v. 55, n. 4, p. 424-429, jul./ago, 2002.

AUSUBEL, D. P.; Novak, J.D.; Hanesian, H. Educational psychology: a cognitive view. 2nd. ed. New York, Holt Rinehart and Winston, 1978.

BEBER, B.; SILVA, E.; BONFIGLIO, S. U. Metacognição como processo da aprendizagem. Rev. Psicopedagogia. v.31, n. 95, p.144-51, 2014.

BRASIL, MEC. Ministério da Educação. Base Nacional Curricular Comum: documento preliminar. Secretaria da Educação Fundamental. Brasília, 2015.

BORUCHOVITCH, E; \& SANTOS, A. A. A. Estratégias de aprendizagem e desempenho acadêmico: evidências de validade. Psicologia: Teoria e Pesquisa, v. 25 n. 4, p.531-536, 2009.

CARVAlHO, H. W. P. de; BATISTA, A. P. de L.; RIBEIRO, C. M. Ensino e aprendizagem de Química na perspectiva dinâmico-interativa. Experiências em Ensino de Ciências. v.2 n. 3, p.34-37, 2007.

CICUTO, C. A. T; CORREIA, P. R. M. Estruturas hierárquicas inapropriadas ou limitadas em mapas Conceituais: um ponto de partida para promover a aprendizagem significativa. Aprendizagem Significativa em Revista, v.. 3, n.1, p. 1-11, 2013.

DAVIES, M. Concept mapping, mind mapping and argument mapping: what are the differences and do they matter? Higher Education, v. 62, n.3, p. 279-301, 2011.

DEFFENDI, L. T.; SCHELINI, P. W. O Monitoramento metacognitivo em tarefas que envolvem a criatividade verbal. Psicologia: Teoria e Pesquisa, v. 32 n. 3, p.1-8, 2016.

FLAVELL, J. Metacognition and cognitive monitoring. American Psychologist. 34, p.906-911. 1979.

GAVA, Tânia Barbosa Salles; MENEZES, CS de; CURY, Davidson. Aplicações de mapas conceituais na educação como ferramenta metacognitiva. In: III International Conference on Engineering and Computer Education-ICECE. 2003.

LEO, C.C.C.; GONÇALVES, A. Modalidades metodológicas em pesquisa científica, a partir de recortes da experiência de saúde coletiva, epidemiologia e atividade física da Unicamp. Revista da Educação Física/UEM, v. 21, n. 3, p. 411-441, 2010.

MELO, K. V.; ZÓFILI, Z. M. S.; CARNEIRO-LEÃO, A. M. A.; OLIVEIRA, G. F. O que sabem e como ensinam os professores: investigando estratégias para mudanças paradigmáticas e de atitudes enfocando a educação ambiental. Amazônia - Revista de Educação em Ciências e Matemáticas, v.8, n. 15, p. 45-60, 2011.

MORAES, J. U; SANTANA, R. G; VIANA-BARBOSA, C. J. Avaliação baseada na Aprendizagem Significativa por meio de Mapas Conceituais. Atas do VIII ENPEC, Campinas 2011.

MORAES, R.; GALIAZZI, M. C. Análise textual discursiva. 2. ed. ljuí: Ed. Unijuí, 2011. 
MOREIRA, M. A. Mapas Conceituais e aprendizagem significativa. São Paulo: Centauro, 2010. MOREIRA, M. A. Teorias De Aprendizagem. São Paulo: EPU, 1999.

MOREIRA, M.A. Mapas conceituais no ensino de Física. Porto Alegre: Instituto de FísicaUFRGS. 1992.

NOVAK, J.D.; GOWIN, D.B. Aprender a aprender. Lisboa: Plátano, 1984.

NOVAK, J. D. Understanding the learning process and effectiveness of teaching methods in the classroom, laboratory and field. Science Education, v. 61, n. 4, p. 453-477, 1977.

NOVAK, J. D. Meaningful learning: The essential factor for conceptual change in limited or inappropriate propositional hierarchies leading to empowerment of learners. Science Education, v. 86, n. 4, p.548-571, 2002.

NUNES, A. S.; ADORNI, D.S. O ensino de química nas escolas da rede pública de ensino fundamental e médio do município de Itapetinga-BA: O olhar dos alunos. In: Atas do Encontro Dialógico Transdisciplinar - Enditrans, 2010, Vitória da Conquista, BA. - Educação e conhecimento científico, 2010.

PACHECO, Sabrina Moro Villela; DAMASIO, Felipe. Mapas conceituais e diagramas V: ferramentas para o ensino, a aprendizagem e a avaliação no ensino técnico. Ciências \& Cognição, v. 14, n. 2, p. 166-193, $2009 .$.

RIBEIRO, C. Metacognição: Um Apoio ao Processo de Aprendizagem. Psicologia: Reflexão e Crítica, v. 16, n. 1, p.109-116, 2003.

RUIZ-MORENO. L.; SONZOGNO, M.C.; BATISTA, S. H. da S.; NILDO, A. B. Mapa conceitual: ensaiando critérios de análise. Revista Ciência e Educação, v.13, n.3, p.453-463, 2007.

SILVA, A. C. R., LACERDA, P. L., CLEOPHAS, M. G. Jogar e compreender a Química: ressignificando um jogo tradicional em didático. Amazônia - Revista de Educação em Ciências e Matemática, v.13, n. 28, p.132-150, 2017.

YANZO, E. O; AMARAL, C. L. C. Mapas conceituais como ferramenta facilitadora na compreensão e interpretação de textos de química. Experiências em Ensino de Ciências, v. 6, n. 3, p.76-86, 2011. 